\section{Filling Biopolis}

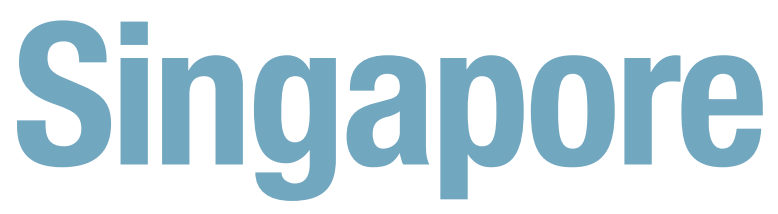

overing 18.5 hectares and encompassing seven buildings, Biopolis is a testament to the Singapore government's commitment to biological research, its proposed 'fourth pillar' of the economy. Officially opening next week, this massive research facility represents one of the largest international scientific recruitment drives ever undertaken in Southeast Asia. Built at a cost of some S\$500 million (US\$290 million), the complex will eventually play host to more than 1,500 scientists.

But this is just the beginning. Singapore's drive to attract high-calibre researchers from around the world will see it expand its scientific infrastructure over the next few years. Biopolis is just part of a larger development covering 200 hectares that will also hold Fusionpolis, a media and information-technology tower, as well as affordable housing for scientists working nearby.

Such levels of investment emphasize the government's commitment to science - but is it enough to entice Westerners away from their labs? In its favour, the city-state's official language is English. However, as well as the long distance from 'home', one other factor that may dissuade Western scientists from heading east is the autocratic reputation of Singapore's government. The centralized nature of the administration is a double-edged sword - on the one hand it allows rapid action, such as the construction of Biopolis in under two years, but on the other it has the potential to stifle scientific autonomy.

So far, Biopolis is seeing an influx of big names to head its research institutes, as well as the beginnings of corporate interest in the complex. Novartis, which plans to move its Institute for Tropical Diseases into one of two Biopolis buildings designated for private

\section{Mixed blessing}

When Lisa Ng (pictured), a native Singaporean, started her postdoc at the Genome Institute of Singapore (GIS), she initially concentrated on hepatitis B. "And then SARS paid a visit," she says. Her background knowledge on the family of coronaviruses - of which SARS (severe acute respiratory syndrome) is a member — was a welcome coincidence. And at the GIS, her group helped to sequence five separate strains in the

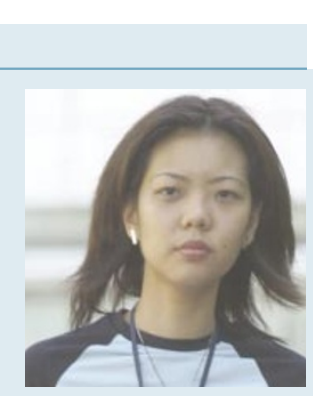
same time frame as it took a US group and a Canadian group to each deliver one. With that work the GIS researchers helped to show that SARS could mutate. $\mathrm{Ng}$ then used that information to develop a genetic screening test for SARS, which has since been licensed by Roche Diagnostics. Awareness of SARS in Singapore had already been high, thanks to posters in taxi cabs and lifts. Now awareness of Singapore science is similarly heightened, thanks to the work on the virus by the Biopolis-based researchers.

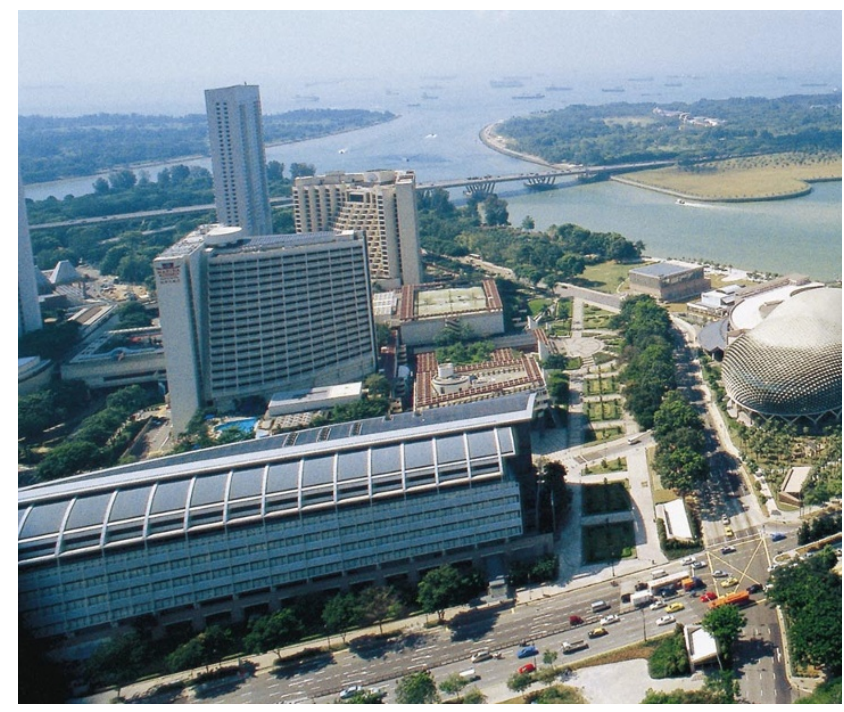

Growth industry: Singapore is investing heavily in science.

tenants, is fulfilling both counts. The institute's director is Alex Matter, former head of oncology research at Novartis, who spearheaded the development of the cancer drug Gleevec.

\section{STARRING INSTITUTES}

Although Novartis is a major tenant, a significant amount of space at Biopolis will be taken up by five research institutes run by the Agency for Science, Technology and Research $\left(A^{\star}\right.$ STAR $)$ - the Genome Institute of Singapore (GIS), the Institute of Bioengineering and Nanotechnology (IBN), the Bioinformatics Institute (BII), the Institute of Molecular and Cell Biology (IMCB) and the Bioprocessing Technology Institute. Philip Yeo, $\mathrm{A}^{\star}$ STAR's director, has spent the past few years securing his own stars to run these divisions. In March 2001, for example, a key member of the team took up his post as director of the GIS. The recruitment of Edison Liu, former head of clinical sciences at the US National Cancer Institute (NCI) in Bethesda, Maryland, sent out a clear signal that Singapore was serious about becoming internationally competitive.

Yeo's most recent coup was convincing Jackie Ying to leave the Massachusetts Institute of Technology (MIT) in Cambridge for Singapore to head the IBN. Ying, who was the youngest tenured professor ever at MIT, could not resist the chance to build something up from nothing. "I wanted an environment where there's a tremendous opportunity to grow," she says.

Ying has already started to build the institute up with researchers from the United States, Europe, Asia and Australia. The IBN has expanded from 20 to over 90 staff since she arrived this March. Eventually it will be home to 250 people, of whom 90 will be permanent staff with $\mathrm{PhDs}$, and 90 a mix of postdocs and graduate students.

The GIS is also set for some significant growth. When the institute launched in 2001 it had a staff of 20 , six of whom were scientists. It is now up to 180 , with plans to grow to about 280 once it moves into Biopolis this year and to 350 by the end of 2005 .

Lance Miller, who followed Liu from the NCI, took about six months to make up his mind to join his mentor. But after visiting Singapore, where he talked to 


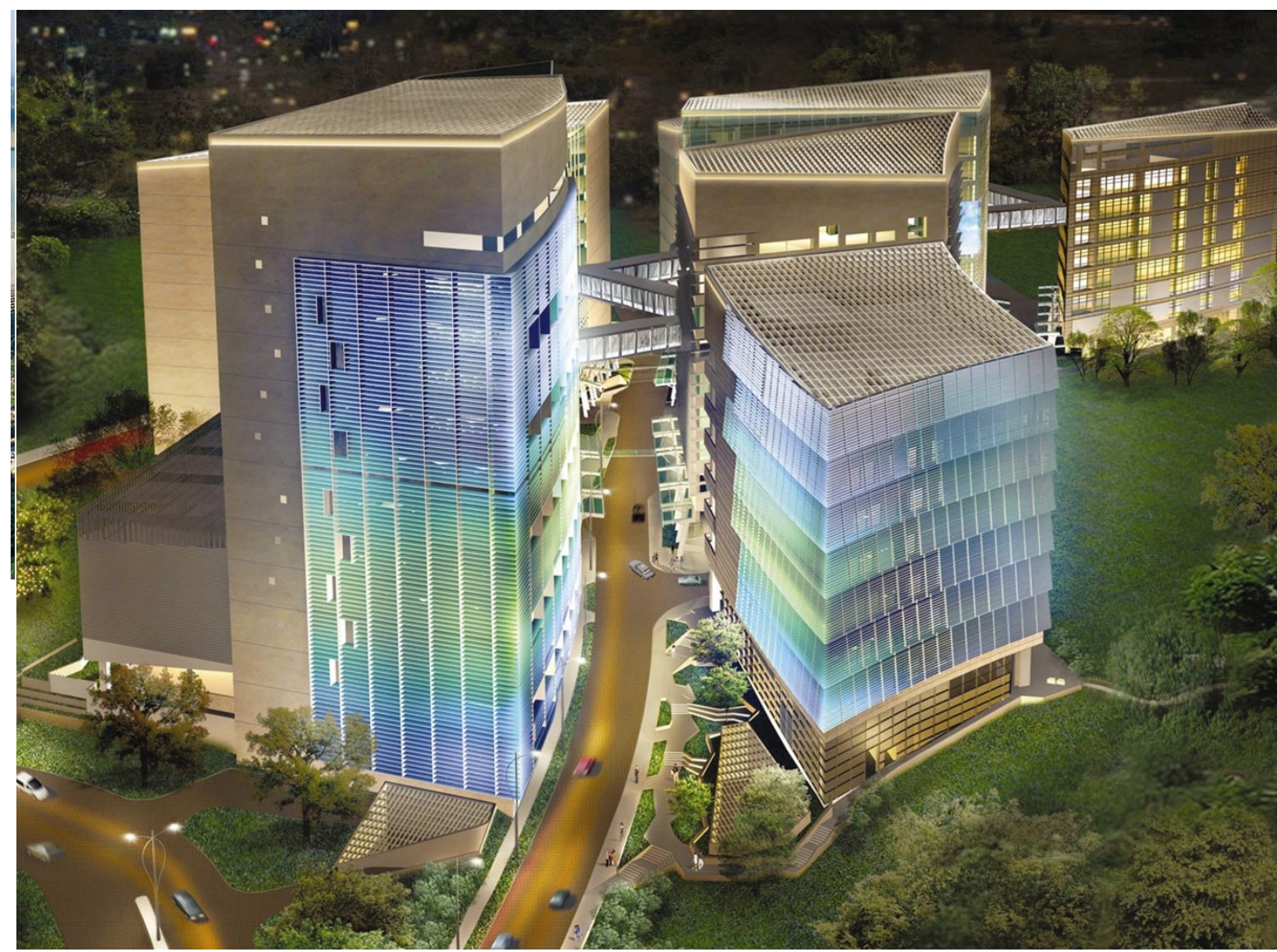

The magnificent seven: when it is completed, the Biopolis complex will be home to around 1,500 scientists.

a number of scientists, he was convinced. The GIS' role in decoding the genome of the virus that causes severe acute respiratory syndrome (SARS) has since validated his decision (see 'Mixed blessing', opposite).

Miller, like many $A^{\star}$ STAR scientists, is excited about the interconnectedness of the Biopolis institutes. Walkways join the GIS and three other $A^{\star}$ Star institutes to one that is central — both literally and figuratively - to them all, the BII, which will provide informatics support to all of the surrounding institutes. Emphasizing the BII's importance, its building also houses the Biopolis cafeteria and lecture halls. "Everyone has to come to the BII for the seminars and the meals," says Gunaretnam Rajagopal, the institute's acting executive director.

The BII, like the other $A^{\star}$ STAR institutes in Biopolis, is on course to grow when it moves in. It has 82 people now, including staff, postdocs and students, and will expand to 100 once it moves in this year, adding another 25 or so in two years' time.

Torsten Exner, a research scientist at the Bioprocessing Technology Institute, was another recruit who initially had doubts about moving to Singapore. "Singapore is not a nation that has a big history of research," Exner says. But while he was completing a postdoc at AstraZeneca in Sweden, Exner did an online search for scientists working in his research speciality and came up with a hit on Singapore. So he moved there in 2002 and has been pleased to be part of the institute's growth - its 70-member staff is set to double by 2005 .

While other $A^{\star}$ STAR institutes are trying to create their own history of research, the oldest, the IMCB, has a head start and is sharpening its focus on developmental biology, structural biology, cancer biology and infectious diseases. Established 16 years ago, the IMCB has grown from 35 people when it opened, to about 400 scientists now. Moving into Biopolis will allow it to expand its number of students and postdocs by $50 \%$. Hong Wanjin, the IMCB's deputy director, says that he is proud that the institute has trained over 100 $\mathrm{PhD}$ students since its inception. Its next step is to grow more Singapore talent. Of the 35 principal investigators now at the IMCB, only six hold Singapore passports.

\section{CENTRALIZED RESERVATIONS}

There are signs, too, that Singapore is overcoming its biggest challenge - growing independent science under an autocratic government. Alan Porter, a principal investigator at the IMCB, joined the institute at its inception. He was attracted by promises that he would be totally funded and independent - a promise that the government has largely kept, he adds. At various times, the government has pushed for more applied research at the IMCB, but has so far accepted that basic as well as applied research can generate intellectual property and contribute to the life-sciences push in Singapore, Porter notes.

For Singapore, the Biopolis infrastructure creates a good foundation. If the country creates a more open scientific culture, the government should have an easy time attracting world-class researchers to its worldclass facility.

Paul Smaglik is editor of Naturejobs.
Web links

Biopolis

www.one-north.com/ pages/lifeXchange/ bio_intro.asp

Agency for Science, Technology and Research

www.a-star.gov.sg/ astar/index.do Genome Institute of Singapore www.gis.a-star.edu.sg Institute of Bioengineering and Nanotechnology

www.ibn.a-star.edu.sg

Bioinformatics Institute www.bil.a-star.edu.sg Institute of Molecular and Cell Biology

www.imcb.a-star.edu.sg Bioprocessing Technology Institute

www.btc.nus.edu.sg Novartis Institute for Tropical Diseases

www.nitd.novartis.com 